\title{
$\beta_{2}-\mathrm{AR}$ 激动剂 $\mathrm{BI}-167107$ 的合成
}

\begin{tabular}{|c|c|c|c|c|}
\hline 王江波 ${ }^{a}$ & Seungkirl Ahn ${ }^{b}$ & Alem W. Kahsai $^{b}$ & 刘 蓉 ${ }^{c}$ & 任 杰 ${ }^{a}$ \\
\hline & 胡 昆 ${ }^{a}$ & 孙小强*,c 陈 & 新*,a & \\
\hline
\end{tabular}

( ${ }^{b}$ Department of Medicine, Duke University Medical Center, Durham, NC 27710, USA)

( 常州大学石油化工学院 常州 213164)

\begin{abstract}
摘要 $\mathrm{BI}-167107$ 是一种新的长效 $\beta_{2}$ 肾上腺素受体 $\left(\beta_{2}-\mathrm{AR}\right)$ 激动剂, 在鉴定 $\mathrm{G}$ 蛋白偶联受体 $(\mathrm{GPCR})$ 配体络合物的结构 方面具有重要应用. 以 2 -硝基间苯二酚为原料, 经过七步反应, 合成了目标化合物, 其结构经 ${ }^{1} \mathrm{H} N \mathrm{NMR},{ }^{13} \mathrm{C} N \mathrm{NR}$ 和 MS 确证. 此合成路线的优点是避免了使用有毒试剂, 可以便捷地用于制备较大量的 BI-167107 及结构相近的苯并噁嗪类 化合物.
\end{abstract}

关键词 BI- $167107 ; \beta_{2}$ 肾上腺素受体; 激动剂; GPCR; 苯并噁嗪; 合成

\section{Synthesis of $\beta_{2}-\mathrm{AR}$ Agonist BI-167107}

\author{
Wang, Jiangbo ${ }^{a}$ \\ Ahn, Seungkirl ${ }^{b}$ \\ Kahsai, Alem W. ${ }^{b}$ \\ Liu, Rong ${ }^{c}$ \\ $\mathrm{Hu}, \mathrm{Kun}^{a} \quad$ Sun, Xiaoqiang ${ }^{*, c}$ Chen, Xin ${ }^{*, a}$ \\ ( ${ }^{a}$ School of Pharmaceutical and Life Science, Changzhou University, Changzhou 213164) \\ ( ${ }^{b}$ Department of Medicine, Duke University Medical Center, Durham, NC 27710, USA) \\ ( ${ }^{c}$ School of Petrochemical Engineering, Changzhou University, Changzhou 213164)
}

Ren, $\mathrm{Jie}^{a}$

\begin{abstract}
BI-167107 is a new long-acting $\beta_{2}$-adrenergic receptor $\left(\beta_{2}\right.$-AR) agonist, and has important application in determining the critical structures of receptor/ligand proteins complex of G-protein-coupled receptor (GPCR). By employing 2-nitroresorcinol as starting material, a practical synthetic route for BI-167107 has been developed, involving 7-step reactions. The structure of the target molecule has been confirmed by ${ }^{1} \mathrm{H}$ NMR, ${ }^{13} \mathrm{C}$ NMR and MS techniques. The advantages of the synthetic route include avoiding use of toxic reagents and being suitable for scale up preparation of BI-167107 and other benzoxazine derivatives.
\end{abstract}

Keywords BI-167107; $\beta_{2}$-adrenergic receptors; agonists; GPCR; benzoxazine; synthesis

$\mathrm{G}$ 蛋白偶联受体 (G protein-coupled receptor, GPCR) 是一大类膜蛋白受体的统称 ${ }^{[1]}$. 这类受体的共同点是其 结构中都有 7 个跨膜 $\alpha$ 螺旋, 且其肽链的 C 端和连接第 5 和第 6 个跨膜螺旋的胞内环上都有 $\mathrm{G}$ 蛋白的结合位点. GPCR 参与了很多细胞信号转导过程, 结合细胞周围环 境中的化学物质并激活细胞内的一系列信号通路, 最终 引起细胞状态的改变 ${ }^{[2,3]}$. 通过调节有关 GPCR 介导的 信号传导可以治疗抑郁症、精神分裂症、失眠高血压、 虚弱、焦躁、紧张、肾功能衰竭、心脑血管疾病和炎症 等病症 ${ }^{[4]}$. 实际上, 目前世界药物市场上大约 $40 \%$ 的药
物都是以 GPCR 作为靶点 ${ }^{[5,6]}$. 这些药物是作为 GPCR 的 激活剂(agonist)或拮抗剂(antagonist) ${ }^{[7]}$. $\beta_{2}$ 肾上腺素能受 体 $\left(\beta_{2}-\mathrm{AR}\right)$ 是一类由肾上腺素激活的 GPCR, 在调节心脑 血管和肺部功能方面具有重要作用, 也是结构和功能被 最广泛研究的膜蛋白之一 ${ }^{[8]}$. $\beta_{2}-\mathrm{AR}$ 激动剂和拮抗剂是 重要的 GPCR 类药物. 其中, $\beta_{2}-A R$ 激动剂由于具有引起 支气管扩张的作用, 故用于治疗哮喘和慢性阻塞性肺疾 病 $(\mathrm{COPD})^{[9]}$. BI-167107 是德国 Boehringer Ingelheim 公 司开发出来的长效 $\beta_{2}$ 受体激动剂(long-acting $\beta_{2}$ agonists, LABA $)^{[10]}$, 其结构中含有苯并噁嗪酮母环和侧链胺基

\footnotetext{
*E-mail: xinchen@cczu.edu.cn; xqsun@jpu.edu.cn

Received November 18, 2012; revised December 6, 2012; published online December 20, 2012.

Project supported by the National Natural Science Foundation of China (Nos. 21272029, 81272982).

国家自然科学基金(Nos. 21272029, 81272982)资助项目.
} 
(Scheme 3).

2011 年, 美国斯坦福大学 Kobilka 教授领导的研究 小组 ${ }^{[11]}$ 利用 BI-167107 同 $\beta_{2}$-AR 的特异性亲合作用, 在 国际上首次得到了活化状态下 $\beta_{2}-A R / G$ 蛋白的络合物 (即 GPCR 的受体/配体络合物)的高清晰度晶体结构. 这 一突破性研究成果为未来开发高效而专一的 $\beta_{2}-\mathrm{AR}$ 类新 药物提供了直接的结构生物学基础, 这也是 Kobilka 教 授获得 2012 年诺贝尔化学奖的重要原因之一. 最近, 本 课题组与美国杜克大学医学中心 Lefkowitz 教授的实验 室合作, 研究另一种重要 GPCR 蛋白 $\beta$-arrestin 的结构与 功能, 因而需要克级数量的 BI-167107. 出于商业利益 考量, Boehringer Ingelheim 公司没有公开发表 BI-167107 的具体合成方法. 因此, 我们针对 BI-167107 的结构特点, 开发出了一条实用的合成路线.

\section{1 结果与讨论}

我们的初步研究结果表明, 尽管 BI-167107 结构中 含有一个手性碳原子, 但在与 $\beta$-arrestin 蛋白的亲合作 用中, BI-167107 的消旋化物与单一对映体并没有表现 出明显的差异. 因此, 本文合成的目标化合物是消旋化 BI-167107. 我们以 2-硝基间苯二酚(1)为起始原料, 在 硝基苯中进行 Fridel-Crafts 酰基化反应, 得到了 2,4-二 差基-3-硝基苯乙酮(2), 接着, 在叔丁基醇锂作用下与 苠溴反应 ${ }^{[12]}$, 生成了 2-羟基-3-硝基-4-芐氧基苯乙酮(3), 产率为 $53 \% .3$ 经过锌粉还原, 将硝基还原成氨基, 得到 了 2 -着基-3-氨基-4-芐氧基苯乙酤(4), 产率为 $82 \%$. 然 后，所得到的羟基苯胺 4 同氯代乙酰氯发生环化反应， 生成了 5-苠氧基-8-乙酰基- $2 H$-苯并 $[1,4]$ 噁溙-3(4H)酮
(5), 产率为 94\% (Scheme 1).

我们最初的合成计划是将 $\mathbf{5}$ 进行氯化, 转变成 $\alpha$-氯 代酮 6, 后者被 $\mathrm{NaBH}_{4}$ 还原成氯代醇 7; 在 7 环化成为 关键的环氧化物 8 后，再同 2-甲基-1-(邻甲苯基)丙基-2胺 (9, Scheme 2)反应, 即可得到 BI-167107 的前体化合 物 15 (Scheme 3). 我们的想法是, 这条路线既可以合成 消旋化目标化合物, 也可以得到 $(R)$-和 $(S)$-构型的最终 产物, 因为 $\alpha$-氯代酠 6 可以在 $\mathrm{CBS}$ 还原条件 ${ }^{[13]}$ 下被还 原成 $(R)$-和 $(S)$-氯代醇, 进而生成相应手性构型的环氧 化物. 遗憾的是, 在 $\mathrm{NaOH}$ 和 $\mathrm{EtOH} /$ 水体系 ${ }^{[14]}$ 中, 氯代 醇 7 无法环化成为环氧化物 8 . 我们尝试了不同的碱和 不同溶剂，均未能得到 $\mathbf{8}$, 只得放弃了该条路线.

胺 9 是通过三步反应得到的(Scheme 2): 2-甲基苯甲 醛(11)与碘化异丙基三苯基磷鎓盐进行 Wittig 反应 ${ }^{[15]}$, 所生成的 1-甲基-2-(2-甲基-1-丙烯基)苯(12)在硫酸作用 下同乙腈发生 Ritter 反应 ${ }^{[16]}$, 得到 $N$-[2-甲基-1-(邻甲苯 基)丙基-2-基]乙酰胺(13); 接着, 在 $\mathrm{KOH}$ 存在下, 并在 乙二醇中高温回流 ${ }^{[17]}, 13$ 水解生成胺 9 . 顺便提一下, 我 们也尝试了 $\alpha$-氯代酮 6 与胺 9 的取代反应, 但未能得到 $\alpha$-氨基酩 10 (Scheme 1).

我们将注意力转到苯并噁嗪乙酮 5 的缩醛化物上. Bouyssou 等 ${ }^{[18]}$ 用 $\mathrm{SeO}_{2}$ 将 4-芐氧基-8-乙酰基- $2 H$-苯并 $[1,4]$ 悪嗪-3 $(4 H)$ 酮氧化为相应的缩醛后, 在乙醇中回流 得到半缩醛, 然后, 与脂肪胺进行缩合反应, 得到相应 的 $\alpha$-氨基酮. BI 公司的 Hoenke 等 ${ }^{[19]}$ 于 2009 年报道了缩 醛 14 同胺 9 的缩合反应，但没有说明 14 的具体合成方 法; 而后者恰恰是合成目标化合物的关键中间体. 我们 尝试用 $\mathrm{SeO}_{2}$ 氧化 5 , 但产率明显偏低. 考虑到 $\mathrm{SeO}_{2}$ 的毒<smiles>CC(=O)c1ccc(O)c([N+](=O)[O-])c1O</smiles>

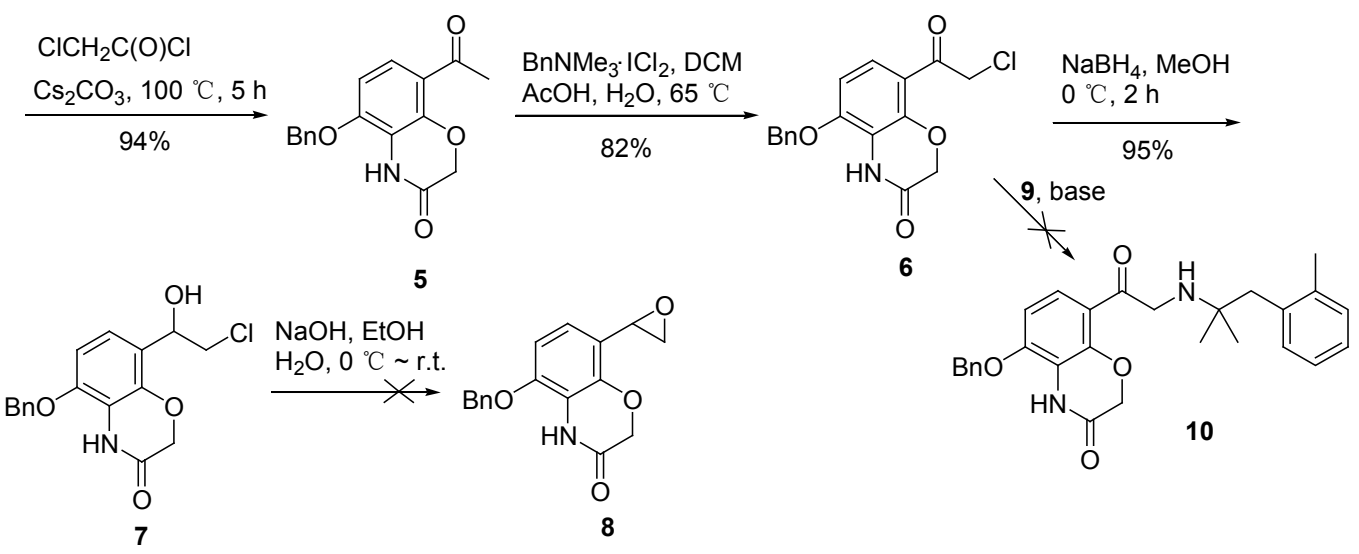

Scheme 1 

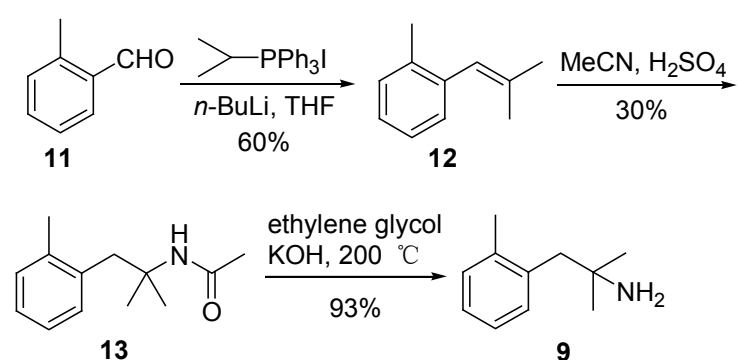

Scheme 2

性, 我们试验了其它的氧化剂, 结果发现, 以 DMSO 作 溶剂, 酮 5 在 $48 \%$ 氢澳酸水溶液 ${ }^{[20]}$ 作用下可以顺利转化 为缩醛 14. 其可能的反应机理是: 氢溴酸与 DMSO 作 用, 生成溴, 二甲硫醚和水; 溴将 $\mathbf{5}$ 进行溴化, 产生 $\alpha$ 溴代酮 $\mathbf{A}$, 进而水解，得到 $\alpha$-羟基酮 $\mathbf{B}$; 接着, $\mathbf{B}$ 被进一 步溴化为 $\alpha$-溴代- $\alpha$-羟基酮 $\mathbf{C}$, 再水解即得到缩醛 14 (Scheme 4). 不太稳定的 14 无需纯化, 直接同胺 9 进行 缩合反应, 所生成的烯胺再被嗍氢化锂还原, 得到羟基 胺 15. 从 5 到 15 三步反应的总产率是 $57 \%$ (Scheme 3). 最后，15 经过催化氢化脱苄基，以 $97 \%$ 的产率生成 BI-167107. 最终产物的结构经过 ${ }^{1} \mathrm{H}$ NMR 和 ${ }^{13} \mathrm{C}$ NMR 以及质谱确证, HPLC 检测纯度在 $98 \%$ 左右. 使用同样 的合成方法, 我们合成了一系列新的苯并噁嗪衍生物, 它们的具体合成方法和生测结果将另文发表.

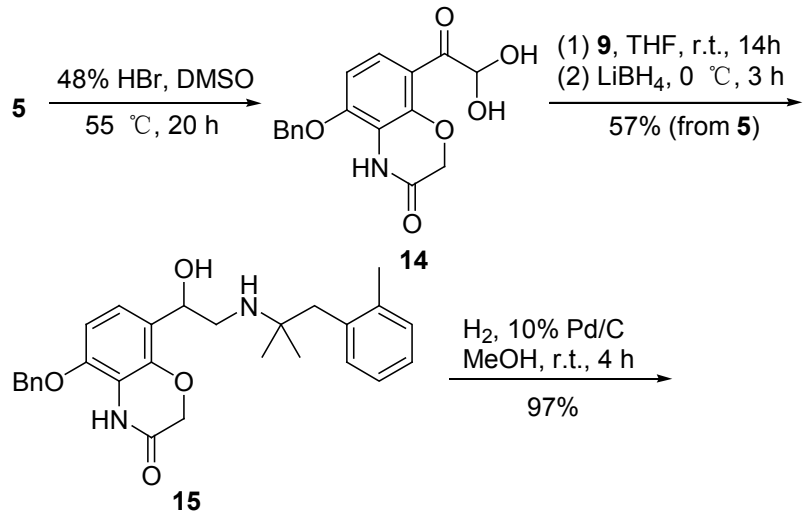<smiles>Cc1ccccc1CC(C)(C)NCC(O)c1ccc(O)c2c1OCC(=O)N2</smiles>

Scheme 3

\section{2 结论}

我们研究了关键中间体 5-芐氧基-8-乙酰基- $2 H$-苯 并 $[1,4]$ 惡溙-3(4H)-酮 $(\mathbf{5})$ 的有关反应，开发了一条实用

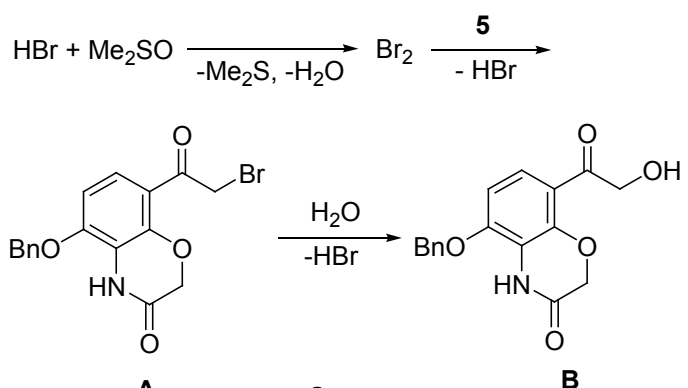

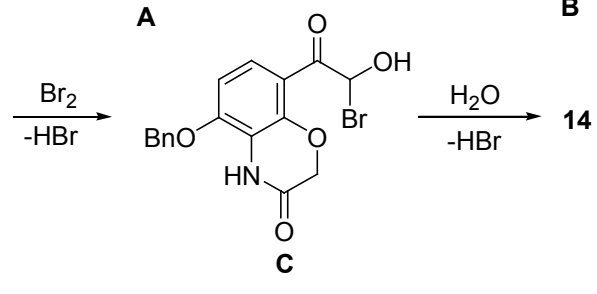

Scheme 4

的合成路线，避免了使用有毒试剂，可以方便地用于制 备较大量的 $\beta_{2}-\mathrm{AR}$ 激动剂 BI-167107. 另外, 此方法也适 用于合成其它的苯并噁嗪衍生物.

\section{3 实验部分}

\section{1 仪器与试剂}

实验中用到的主要仪器有：DHG-9240A 型电热恒 温鼓风干燥箱(上海精宏实验设备有限公司); RE-522A 型旋转蒸发仪 (上海亚荣生化仪器厂); AL204 型分析天 平(梅特勒-托利多仪器(上海)有限公司); ZF-I 型三用紫 外分析仪 (上海顾林电光仪器厂); 安捷伦 1260 型 HPLC; 安捷伦 7820A 型 GC; 岛津 2020 型 LC-MS; Bruker AVANCE 300/400 MHz 核磁共振仪(TMS 为内标).

实验所用化学试剂和生产厂家包括: 2-硝基间苯二 酚 (98\%，安耐吉)，醋酸䣶(AR,阿拉丁), 无水氯化铝 (AR，阿拉丁)，硝基苯(AR，阿拉丁)，溴芐( $99 \%$ ，阿拉 丁)，叔丁基醇锂(97\%,Sigma-Aldrich)，锌粉(AR，江苏 永丰化学试剂厂), 乙酸(AR, 阿拉丁), 氯乙酰氯 $(98 \%$, 阿拉丁), 碳酸铯( $99 \%$,Sigma-Aldrich), 48\%氢澳酸水溶 液(安耐吉), 二甲基亚砜( $\mathrm{AR}$, 上海晶纯试剂有限公司), 硼氢化锂 $(95 \%$,阿拉丁), $10 \% \mathrm{Pd} / \mathrm{C}(\mathrm{AR}$ ，上海晶纯试剂 有限公司), 2-甲基苯甲醛( $99 \%$, 阿拉丁); 碘化异丙基三 苯基磷鎓( $98 \%$, 安耐吉), 正丁基锂(2.5 M 正己烷溶液; 萨恩化学技术(上海)有限公司), 乙腈(AR,上海凌峰化学 试剂有限公司)，乙二醇(AR，江苏强盛化工有限公司); 其余所用溶剂(石油醚，二氯甲烷，乙酸乙酯)均为分析 纯.

\section{2 实验方法}

\subsubsection{2,4-二羟基-3-硝基苯乙酮(2)的合成}

氮气保护下, 在 $250 \mathrm{~mL}$ 三口烧瓶中分别加入硝基 苯 $(135 \mathrm{~mL})$ 和 $\mathrm{AlCl}_{3}(1.91 \mathrm{~g}, 14.32 \mathrm{mmol})$, 搅拌 $10 \mathrm{~min}$, 
再慢慢向混合溶液中分批加入 2-硝基间苯二酚(10.00 g, $64.50 \mathrm{mmol})$, 再向溶液中滴加 $\mathrm{Ac}_{2} \mathrm{O}(6.40 \mathrm{~mL})$, 于 100 ${ }^{\circ} \mathrm{C}$ 下反应 $5 \mathrm{~h}$. 停止加热后, 冷却到室温, 将反应液倒入 冰冷的 $2 \mathrm{~mol} / \mathrm{L} \mathrm{HCl}(120 \mathrm{~mL})$ 中淬灭反应. 混合液用乙 醚萃取 $(200 \mathrm{~mL} \times 2)$, 合并有机相. 将有机相用 $2 \mathrm{~mol} / \mathrm{L}$ $\mathrm{NaOH}$ 萃取 $(150 \mathrm{~mL} \times 2)$, 合并水相. 合并得到的水相用 乙醚洗涤 $(50 \mathrm{~mL} \times 4)$ 后, 再用 $2 \mathrm{~mol} / \mathrm{L} \mathrm{HCl}$ 调节到 $\mathrm{pH}=$ 1. 将生成的沉淀抽滤, 水洗, 于空气中干燥, 得到暗黄 色固体. 粗产物经柱层析纯化 [洗脱剂: $V$ (二氯甲烷)： $V($ 石油醚 $)=3: 1$ ], 得到亮黄色固体 $2(8.64 \mathrm{~g})$, 产率 68\%. ${ }^{1} \mathrm{H}$ NMR (300 MHz, $\mathrm{CDCl}_{3}$ ) $\delta: 14.85(\mathrm{~s}, 1 \mathrm{H}), 11.35$ (s, 1H), $7.90(\mathrm{~d}, J=9.09 \mathrm{~Hz}, 1 \mathrm{H}), 6.63(\mathrm{~d}, J=9.09 \mathrm{~Hz}$, $1 \mathrm{H}), 2.62(\mathrm{~s}, 3 \mathrm{H})$.

\subsubsection{2-羟基-3-硝基-4-苄氧基苯乙酮(3)的合成}

在 $250 \mathrm{~mL}$ 三口烧瓶中, 将 $2(8.64 \mathrm{~g}, 64.5 \mathrm{mmol})$ 溶 于 DMF $(85 \mathrm{~mL})$ 中, 在氮气保护下加入 $\operatorname{LiOBu}-t(3.51 \mathrm{~g})$, 室温下摚拌 $10 \mathrm{~min}$. 加入芐澳 $(5.21 \mathrm{~mL})$, 室温下摚拌 20 $\mathrm{h}$ 后, 将反应液倒入冰水 $(50 \mathrm{~mL})$ 中淬灭反应. 加入 1 $\mathrm{mol} / \mathrm{L} \mathrm{NaOH}(43 \mathrm{~mL})$, 用乙醚洗涤 $(200 \mathrm{~mL} \times 2)$. 冰水浴 条件下, 用 $2 \mathrm{~mol} / \mathrm{L} \mathrm{HCl}(173 \mathrm{~mL})$ 酸化至 $\mathrm{pH}=1$, 有沉淀 生成. 抽滤, 水洗, 于空气中干燥, 得到黄色固体. 粗产 物经柱层析纯化 [洗脱剂: $V$ (二氯甲烷) $: V$ (石油醚 $)=$ $5: 1$ ], 得到淡黄色固体 3 (6.72 g), 产率 53\%. ${ }^{1} \mathrm{H}$ NMR $\left(300 \mathrm{MHz}, \mathrm{CDCl}_{3}\right) \delta: 13.07(\mathrm{~s}, 1 \mathrm{H}), 7.76(\mathrm{~d}, J=9.06 \mathrm{~Hz}$, $2 \mathrm{H}), 7.41 \sim 7.31(\mathrm{~m}, 5 \mathrm{H}), 6.58(\mathrm{~d}, J=9.06 \mathrm{~Hz}, 1 \mathrm{H}), 5.25$ (s, 2H), 2.58 (s, 3H).

\subsubsection{2-羟基-3-氨基-4-芐氧基苯乙酮(4)的合成}

在 $250 \mathrm{~mL}$ 三口烧瓶中, 将 $\mathbf{3}(6.72 \mathrm{~g}, 23.4 \mathrm{mmol})$ 溶 于 $\mathrm{AcOH}(68 \mathrm{~mL})$ 中, 慢慢分批加入 $\mathrm{Zn}$ 粉 $(6.72 \mathrm{~g})$, 室温 下搅拌 $2 \mathrm{~h}$. 抽滤, 将滤液倒入冰水 $(680 \mathrm{~mL})$ 中, 生成沉 淀, 抽滤, 于空气中干燥, 得到黄色固体. 粗产物经柱 层析纯化[洗脱剂: $V$ (二氯甲烷) $: V$ (石油醚) $=1: 1$ ], 得 到黄色固体 4 (4.9 g), 收率 82\%. ${ }^{1} \mathrm{H}$ NMR $(300 \mathrm{MHz}$, $\left.\mathrm{CDCl}_{3}\right) \delta: 12.49(\mathrm{~s}, 1 \mathrm{H}), 7.45 \sim 7.34(\mathrm{~m}, 5 \mathrm{H}), 7.16(\mathrm{~d}, J=$ $8.91 \mathrm{~Hz}, 1 \mathrm{H}), 6.50$ (d, $J=8.94 \mathrm{~Hz}, 1 \mathrm{H}), 5.17$ (s, 2H), 2.55 (s, $3 \mathrm{H})$.

3.2.4 5-芐氧基-8-乙酰基- $2 H$-苯并 $[1,4]$ 啞嗪- $3(4 H)$ 酮(5)的合成

在 $100 \mathrm{~mL}$ 三口烧瓶中, 分别加入 $4(4.9 \mathrm{~g}, 19.0$ $\mathrm{mmol}), \mathrm{NaHCO}_{3}(3.54 \mathrm{~g})$ 和 DMF $(30 \mathrm{~mL})$. 搅拌溶解后, 向混合液中滴加氯乙酰氯 $(1.70 \mathrm{~mL})$, 室温搅拌 $2 \mathrm{~h}$ 后, 加入 $\mathrm{Cs}_{2} \mathrm{CO}_{3}(7.45 \mathrm{~g})$, 加热到 $100{ }^{\circ} \mathrm{C}$, 反应 $5 \mathrm{~h}$. 冷却到 室温, 将反应液倒入水 $(470 \mathrm{~mL})$ 中淬灭反应. 用乙酸乙 酯萃取 $(190 \mathrm{~mL} \times 2)$ 后, 分别用水 $(280 \mathrm{~mL} \times 2)$ 和饱和食 盐水 $(150 \times 2 \mathrm{~mL})$ 洗涤, 无水硫酸钠干燥, 过滤, 减压蒸
馏得黄色固体. 粗产物经柱层析纯化 [洗脱剂: $V$ (二氯甲 烷) : $V$ (石油醚 $)=3: 1$ ], 得到浅黄色固体 $5(5.30 \mathrm{~g})$, 产 率 94\%. ${ }^{1} \mathrm{H}$ NMR $\left(300 \mathrm{MHz}, \mathrm{CDCl}_{3}\right) \delta: 7.98(\mathrm{~s}, 1 \mathrm{H}), 7.55$ (d, $J=8.88 \mathrm{~Hz}, 1 \mathrm{H}), 7.42 \sim 7.37(\mathrm{~m}, 5 \mathrm{H}), 6.71(\mathrm{~d}, J=8.91$ $\mathrm{Hz}, 1 \mathrm{H}), 5.15$ (s, 2H), 4.68 (s, 2H), 2.59 (s, 3H).

3.2 .5 - 芐氧基- 8 -(2-氯乙酰基)- $2 H$-苯并 $[1,4]$ 噁嗪$3(4 H)$-酮 $(6)$ 的合成

在 $250 \mathrm{~mL}$ 三口烧瓶中, 依次加入二氯甲烷 $(100$ $\mathrm{mL}), \mathrm{AcOH}(32 \mathrm{~mL}), \mathrm{H}_{2} \mathrm{O}(5 \mathrm{~mL})$, 和 $5(5.30 \mathrm{~g}, 17.8$ $\mathrm{mmol})$, 室温摚拌溶解, 然后, 向混合液中加入苠基三 甲基二氯碘酸铵 $(13.66 \mathrm{~g}, 39.2 \mathrm{mmol})$, 加热到 $100{ }^{\circ} \mathrm{C}$, 反应 $20 \mathrm{~h}$. 冷却到室温. 在 $500 \mathrm{~mL}$ 三口烧瓶中, 将反应 液倒入 $5.5 \% \mathrm{NaHSO}_{3}$ 溶液 $(102 \mathrm{~mL})$ 中, 室温摚拌 $30 \mathrm{~min}$. 加入乙醚 $(190 \mathrm{~mL})$, 有沉淀生成, 抽滤, 依次用适量水 和乙醚洗涤, 于空气中干燥, 得到棕色固体. 粗产物经 柱层析纯化 [洗脱剂: $V$ (二氯甲烷) $: V$ (石油醚) $=2 ： 1$ ], 得到淡黄色固体 6 (4.68 g), 产率 79\%. ${ }^{1} \mathrm{H}$ NMR (400 $\left.\mathrm{MHz}, \mathrm{CDCl}_{3}\right) \delta: 7.85(\mathrm{~s}, 1 \mathrm{H}), 7.65(\mathrm{~d}, J=7.65 \mathrm{~Hz}, 1 \mathrm{H})$, $7.43 \sim 7.38(\mathrm{~m}, 5 \mathrm{H}), 6.77(\mathrm{~d}, J=8.00 \mathrm{~Hz}, 1 \mathrm{H}), 5.17(\mathrm{~s}$, $2 \mathrm{H}), 4.74$ (s, 2H), 4.69 (s, 2H).

3.2.6 5-芐氧基-8-[(2-氯-1-羟基) 乙基 $]-2 H$-苯并 $[b]$ $[1,4]$ 腎嗪-3(4H)-酮 $(7)$ 的合成

在 $25 \mathrm{~mL}$ 三口烧瓶中, 将 $6(150 \mathrm{mg}, 0.45 \mathrm{mmol}$ )溶 于 $\mathrm{MeOH}(5 \mathrm{~mL})$ 中. 冰浴条件下，向混合液中加入硼氢 化钠 $(26 \mathrm{mg}, 0.68 \mathrm{mmol}), 0{ }^{\circ} \mathrm{C}$ 条件下反应 $2 \mathrm{~h}$. 将反应液 小心倒入水 $(2.0 \mathrm{~mL})$ 中淬灭反应, 减压蒸馏除去 $\mathrm{MeOH}$, 用乙酸乙酯萃取 $(10 \mathrm{~mL} \times 2)$, 萃取液分别用水 $(2 \times 5$ $\mathrm{mL})$ 和饱和食盐水 $(5 \mathrm{~mL} \times 2)$ 洗涤, 无水硫酸钠干燥, 过 滤, 减压蒸馏得白色固体. 粗产物经柱层析纯化 [洗脱 剂: $V$ (二氯甲烷) $: V($ 石油醚 $)=3: 1$ ], 得到白色固体 7 (140 mg), 产率 93\%. ${ }^{1} \mathrm{H}$ NMR (300 MHz, $\left.\mathrm{CDCl}_{3}\right) \delta: 7.82$ (s, 1H), $7.41 \sim 7.37(\mathrm{~m}, 5 \mathrm{H}), 7.10(\mathrm{~d}, J=8.64 \mathrm{~Hz}, 1 \mathrm{H})$, $6.68(\mathrm{~d}, J=8.67 \mathrm{~Hz}, 1 \mathrm{H}), 5.08 \sim 5.12(\mathrm{~m}, 1 \mathrm{H}), 5.09$ (s, 2H), $4.64(\mathrm{~d}, J=15.3 \mathrm{~Hz}, 1 \mathrm{H}), 4.59$ (d, $J=15.3 \mathrm{~Hz}, 1 \mathrm{H})$, 3.79 (dd, $J=3.5,11.0 \mathrm{~Hz}, 1 \mathrm{H}), 3.61(\mathrm{dd}, J=2.7,11.0 \mathrm{~Hz}$, $1 \mathrm{H}), 2.72(\mathrm{~d}, J=4.50 \mathrm{~Hz}, 1 \mathrm{H})$.

\subsubsection{2-甲基-1-(邻甲苯基)丙基-2-胺(9)的合成}

在 $250 \mathrm{~mL}$ 三口烧瓶中, 加入碘化异丙基三苯基磷 鑤 $(20 \mathrm{~g}, 46.3 \mathrm{mmol})$ 和无水四氢呋喃 $(20 \mathrm{~mL})$. 冷却至 0 ${ }^{\circ} \mathrm{C}$, 向反应液中加入正丁基锂 $(2.5 \mathrm{~mol} / \mathrm{L}$ 己烷溶液; 20 $\mathrm{mL}, 50 \mathrm{mmol}$ ), 搅拌半小时后，加入 2-甲基苯甲醛(5.56 $\mathrm{g}, 46.3 \mathrm{mmol})$ 与四氢呋喃 $(50 \mathrm{~mL})$ 的混合液, 室温反应 $20 \mathrm{~h}$. 将反应液小心倒入冰水 $(130 \mathrm{~mL})$ 中淬灭反应，用 乙酸乙酯萃取 $(50 \mathrm{~mL} \times 3)$, 用水 $(30 \mathrm{~mL} \times 2)$ 和饱和食盐 水 $(30 \mathrm{~mL} \times 2)$ 分别洗涤, 用无水硫酸镁干燥, 过滤, 减 
压蒸馏, 粗产物经柱层析纯化(洗脱剂: 石油醚), 得到 透明液体 12 (4.04 g), 产率 60\%. ${ }^{1} \mathrm{H}$ NMR (300 MHz, $\left.\mathrm{CDCl}_{3}\right) \delta: 7.18 \sim 7.10(\mathrm{~m}, J=3.78 \mathrm{~Hz}, 4 \mathrm{H}), 6.23(\mathrm{~s}, 1 \mathrm{H})$, $2.25(\mathrm{~s}, 3 \mathrm{H}), 1.92(\mathrm{~s}, 3 \mathrm{H}), 1.72(\mathrm{~s}, 3 \mathrm{H})$.

将 12 (4.04 g, $27.6 \mathrm{mmol})$ 溶于乙腈 $(9.5 \mathrm{~mL})$ 中, 在冰 水浴条件下, 分批加入浓硫酸 $(5.60 \mathrm{~mL})$, 室温反应 $17 \mathrm{~h}$. 将反应液倒入冰水 $(180 \mathrm{~mL})$ 中淬灭反应，用 $10 \mathrm{~mol} / \mathrm{L}$ $\mathrm{NaOH}$ 溶液调节溶液 $\mathrm{pH}=7$, 用乙酸乙酯萃取 $(40$ $\mathrm{mL} \times 3)$, 用水 $(30 \mathrm{~mL} \times 2)$ 和饱和食盐水 $(30 \mathrm{~mL} \times 2)$ 分别 洗涤, 无水硫酸镁干燥, 过滤, 减压蒸馏, 柱层析纯化 [洗脱剂: $V$ (二氯甲烷) $: V$ (石油醚 $)=3: 1$ ], 得到淡黄色 固体 13 (1.70 g), 产率 $30 \% .{ }^{1} \mathrm{H} \mathrm{NMR}\left(300 \mathrm{MHz}, \mathrm{CDCl}_{3}\right)$ $\delta: 7.15 \sim 7.09(\mathrm{~m}, 4 \mathrm{H}), 5.21(\mathrm{~s}, 1 \mathrm{H}), 3.09(\mathrm{~s}, 2 \mathrm{H}), 2.34(\mathrm{~s}$, $3 \mathrm{H}), 1.93$ (s, 3H), 1.33 (s, 6H).

在 $50 \mathrm{~mL}$ 三口烧瓶中, 加入 13 (1.70 g, $8.28 \mathrm{mmol})$, 乙二醇 $(20 \mathrm{~mL})$ 和 $\mathrm{KOH}(3.00 \mathrm{~g}, 53.6 \mathrm{mmol})$, 于 $200{ }^{\circ} \mathrm{C}$ 下 反应 $24 \mathrm{~h}$. 冷却至室温, 将反应液倒入饱和食盐水 $(50$ $\mathrm{mL})$ 中, 用乙酸乙酯萃取 $(30 \mathrm{~mL} \times 3)$, 用水 $(20 \mathrm{~mL} \times 2)$ 和饱和食盐水 $(20 \mathrm{~mL} \times 2)$ 分别洗涤, 无水硫酸镁干燥, 过滤, 减压蒸馏, 粗产物经柱层析纯化 [洗脱剂: $V($ 二氯 甲烷) $: V$ (甲醇 $)=60 ： 1]$, 得到黄色液体 9 (1.25 g), 产 率 93\%. ${ }^{1} \mathrm{H}$ NMR $\left(300 \mathrm{MHz}, \mathrm{CDCl}_{3}\right) \delta: 7.18 \sim 7.11(\mathrm{~m}$, 4H), $2.72(\mathrm{~s}, 2 \mathrm{H}), 2.36(\mathrm{~s}, 3 \mathrm{H}), 1.14(\mathrm{~s}, 6 \mathrm{H})$; ESI-MS: $\mathrm{m} / \mathrm{z}$ $164[\mathrm{M}+\mathrm{H}]^{+}$.

3.2.8 5- 芐氧基-8-(2,2-二羟基乙酰基)- $2 \mathrm{H}$ - 苯并 $[b][1,4]$ 噁嗪-3(4H)-酮(14)的合成

在 $50 \mathrm{~mL}$ 单口烧瓶中, 加入 5 (1.08 g, $3.6 \mathrm{mmol})$, DMSO $(10 \mathrm{~mL})$ 和 $48 \% \mathrm{HBr}(1.5 \mathrm{~mL})$, 加热至 $55^{\circ} \mathrm{C}$, 反应 $20 \mathrm{~h}$. 冷却至室温, 将反应液倒入冰水 $(50 \mathrm{~mL})$ 中淬灭反 应, 用乙酸乙酯 $(60 \mathrm{~mL} \times 3)$ 萃取, 合并萃取液用水 $(50$ $\mathrm{mL} \times 2)$ 和饱和食盐水 $(50 \mathrm{~mL} \times 2)$ 分别洗涤, 无水硫酸钠 干燥, 过滤, 减压蒸馏, 得到黄色固体 14, 未经纯化, 直接投入下一步反应.

3.2 .95 -芐氧基-8-(1-羟基-2-((2-甲基-1-(邻甲苯基) 丙-2-基)氨基) 乙基)- $2 H$-苯并 $[b][1,4]$ 噁嗪-3(4H)-酮 (15)的合成

在 $50 \mathrm{~mL}$ 三口烧瓶中, 将上步得到的 14 溶于四氢 呋喃(22 mL)中, 加入 7 (0.63 g, $3.87 \mathrm{mmol})$, 室温下反应 $14 \mathrm{~h}$. 将反应混合物冷却至 $0{ }^{\circ} \mathrm{C}$ 后, 加入 $\mathrm{LiBH}_{4}(0.23 \mathrm{~g}$, $10.6 \mathrm{mmol}$ ), 并在 $0{ }^{\circ} \mathrm{C}$ 下反应 $3 \mathrm{~h}$. 将反应液小心倒入冰 水 $(55 \mathrm{~mL})$ 中淬灭反应，用二氯甲烷(100 $\mathrm{mL} \times 3)$ 萃取， 合并萃取液用水 $(50 \mathrm{~mL} \times 2)$ 和饱和食盐水 $(50 \mathrm{~mL} \times 2)$ 分 别洗涤, 无水硫酸钠干燥. 粗产物经过柱层析纯化 [洗 脱剂: $V$ (二氯甲烷 $) ： V($ 甲醇 $)=50 ： 1 ; V$ 二氯甲烷 $)$ : $V($ 甲醇 $)=20: 1]$, 得到黄色固体 $15(0.95 \mathrm{~g})$, 产率 $57 \%$.
${ }^{1} \mathrm{H}$ NMR (400 MHz, $\left.\mathrm{CDCl}_{3}\right) \delta: 7.73(\mathrm{~s}, 1 \mathrm{H}), 7.42 \sim 7.37$ $(\mathrm{m}, 5 \mathrm{H}), 7.20 \sim 7.16(\mathrm{~m}, 5 \mathrm{H}), 6.64(\mathrm{~d}, J=8.00 \mathrm{~Hz}, 1 \mathrm{H})$, $5.52(\mathrm{~d}, J=12.00 \mathrm{~Hz}, 1 \mathrm{H}), 5.07$ (s, 2H), 4.57 (d, $J=16.00$ $\mathrm{Hz}, 1 \mathrm{H}), 4.34$ (d, $J=16.00 \mathrm{~Hz}, 1 \mathrm{H}), 3.35$ (d, $J=12.00 \mathrm{~Hz}$, $1 \mathrm{H}), 3.19 \sim 3.24(\mathrm{~m}, 1 \mathrm{H}), 3.02(\mathrm{t}, J=12.00 \mathrm{~Hz}, 1 \mathrm{H}), 2.37$ (s, 3H), 1.38 (s, 6H); ESI-MS: $m / z 461[\mathrm{M}+\mathrm{H}]^{+}$.

3.2 .105 -差基-8-(1-差基-2-[(2-甲基-1-(邻甲苯基) 丙-2-基)氨基]乙基)- $2 H$-苯并 $[b][1,4]$ 啞嗪-3(4H)-酮 (BI-167107) 的合成

在 $50 \mathrm{~mL}$ 单口烧瓶中, 将 $\mathbf{1 5}(0.95 \mathrm{~g}, 2.06 \mathrm{mmol})$ 溶 解于 $\mathrm{MeOH}(20 \mathrm{~mL})$ 中, 加入 $10 \% \mathrm{Pd} / \mathrm{C}(200 \mathrm{mg})$, 在常 温常压下催化氢化 $4 \mathrm{~h}$. 用硅藻土滤除催化剂后, 粗产 物经柱层析纯化 [洗脱剂: $V$ (二氯甲烷) $: V$ (甲醇 $)=30$ : $1]$, 得到淡黄色固体 BI-167107 (0.74 g), 产率 97\%. ${ }^{1} \mathrm{H}$ NMR (400 MHz, DMSO-d $) \delta: 9.92$ (s, 1H), 7.15 7.06 $(\mathrm{m}, 4 \mathrm{H}), 6.90(\mathrm{~d}, J=8.64 \mathrm{~Hz}, 1 \mathrm{H}), 6.52(\mathrm{~d}, J=8.43 \mathrm{~Hz}$, $1 \mathrm{H}), 4.85$ (d, $J=5.58 \mathrm{~Hz}, 1 \mathrm{H}), 4.48$ (d, $J=1.83 \mathrm{~Hz}, 2 \mathrm{H})$, $2.72(\mathrm{~d}, J=1.83 \mathrm{~Hz}, 1 \mathrm{H}), 2.63(\mathrm{t}, J=9.00 \mathrm{~Hz}, 1 \mathrm{H}), 2.29$ (s, $3 \mathrm{H}), 1.86(\mathrm{~s}, 2 \mathrm{H}), 1.00(\mathrm{~s}, 6 \mathrm{H}) ;{ }^{13} \mathrm{C} \mathrm{NMR}(100 \mathrm{MHz}$, DMSO- $\left.d_{6}\right) \delta: 164.43,144.23,141.20,136.87,136.42$, $131.29,130.20,126.08,125.19$, 122.03, 115.15, 108.99, $66.94,65.82,55.12,48.36,41.77,25.81,25.50,20.19$; ESI-MS: $m / z: 371[\mathrm{M}+\mathrm{H}]^{+}$.

致谢 我们衷心感谢 2012 年诺贝尔化学奖获得者、美 国杜克大学医学中心 Robert J. Lefkowitz 教授对本课题 的慷慨支持和鼓励.

\section{References}

[1] Lu, S.-Y.; Jiang, Y.-J.; Yu, Q.-S.; Zou, J.-W. Acta Chim. Sinica 2009, 67, 1553 (in Chinese) (陆绍永, 蒋勇军, 俞庆森, 邹建卫, 化学学报, 2009, 67, 1553.)

[2] Pierce, K. L.; Premont, R. T.; Lefkowitz, R. J. Nat. Rev. Mol. Cell Biol. 2002, 3, 639.

[3] Fredriksson, R.; Schioth, H. B. Mol. Pharm. 2005, 67, 1414.

[4] Hong, M.-H.; Chi, Z.-Q; Liu, J.-G. Chin. Pharm. Bull. 2005, 21, 1030 (in Chinese). (洪民华, 池志强, 刘景根, 中国药理学通报, 2005, 21, 1030.)

[5] Filmore, D. Modern Drug Discovery 2004, 24.

[6] Overington, J. P.; Al-Lazikani, B.; Hopkins, A. L. Nat. Rev. Drug Discovery 2006, 5, 993.

[7] Yin, Y.-B.; Luo, J.-C.; Jiang, Y. Chin. Sci. Bull. 2003, 48, 307 (in Chinese). (尹燕斌, 罗静初, 姜颖, 科学通报, 2003, 48, 307).

[8] Lefkowitz, R. J. Nat. Cell Biol. 2000, 2, E133.

[9] Sears, M. R.; Lotvall, J. Respir. Med. 2005, 99, 152.

[10] Tautermann, C. S.; Pautsch, A. Med. Chem. Lett. 2011, 2, 414

[11] Rasmussen, S. G.; DeVree, B. T.; Zou, Y.; Kruse, A. C.; Chung, K. Y.; Kobilka, T. S.; Thian, F. S.; Chae, P. S.; Pardon, E.; Calinski, D.; Mathiesen, J. M.; Shah, S. T.; Lyons, J. A.; Caffrey, M.; Gellman, S. H.; Steyaert, J.; Skiniotis, G.; Weis, W. I.; Sunahara, R. K.; 
Kobilka, B. K. Nature 2011, 477, 549 .

[12] Alcaraz, L.; Kindon, N.; Sutton, J. M. WO 2008/149110, 2008 [Chem. Abstr. 2008, 150, 34973].

[13] Corey, E. J.; Bakshi, R. K.; Shibata, S. J. Am. Chem. Soc. 1987, $109,5551$.

[14] Mangas-Sanchez, J.; Busto, E.; Gotor-Fernandez, V.; Malpartida, F.; Gotor, V. J. Org. Chem. 2011, 76, 2115.

[15] Goldfuss, B.; Denisenko, D.; Kulhanek, J. Chem. Eur. J. 2004, 10, 4252.

[16] Ritter, J. J.; Minieri, P. P. J. Am. Chem. Soc.1948, 70, 4045.
[17] Florvall, L.; Fagerval1, I.; Ask, A.-L.; Ross, S. B. J. Med. Chem. 1986, 29, 2250.

[18] Bouyssou, T.; Hoenke, C.; Rudolf, K.; Lustenberger, P.; Pestel, S.; Sieger, P.; Lotz, R.; Heine, C.; Büttner, F. H.; Schnapp, A.; Konetzki, I. Bioorg. Med. Chem. Lett. 2010, 20, 1410.

[19] Hoenke, C.; Bouyssou, T.; Tautermann, C. S.; Rudolf, K.; Schnapp, A.; Konetzki, I. Bioorg. Med. Chem. Lett. 2009, 19, 6640.

[20] Floyd, M. B.; Du, M. T.; Fabio, P. F.; Jacob, L. A.; Johnson, B. D. J. Org. Chem. 1985, 50, 5022. 